\title{
O PROCESSO DE DEMARCAÇÃO DAS TERRAS TRADICIONAIS INDÍGENAS NA REGIÁO SUL DO BRASIL: UMA ANÁLISE DOS OBSTÁCULOS JURÍDICOS E POLIITICOS
}

\author{
THE PROCESS OF DEMARCATION OF TRADITIONAL \\ LANDS IN THE SOUTHERN BRAZIL REGION: \\ AN ANALYSIS OF LEGAL AND POLITICAL OBSTACLES
}

PEDRO LUIS LOCKS JUSTI ${ }^{1}$

DANIEL RIBEIRO PREVE ${ }^{2}$

RESUMO

O estudo proposto tem como objetivo analisar a problemática da demarcação das terras indígenas na Região Sul do Brasil. Inicialmente abordou-se os aspectos históricos, conceitos relevantes, direitos e garantias constitucionais dos povos indígenas e as políticas intervencionistas na defesa destes povos. Neste sentido, destacou-se o papel da FUNAI como órgão responsável direto pelas demarcações, mas, especialmente a situação atual dos processos de regularização das áreas indígenas. Foi utilizado como metodologia científica o método dedutivo em exploração teórica e qualitativa com a utilização de material bibliográfico e documental legal. Constatou-se que um dos principais obstáculos para as efetivas demarcações das terras indígenas está ligado à ausência de políticas públicas, em que os interesses de determinados grupos se sobrepõem aos interesses difusos e coletivos. Além disso, a falta de servidores públicos capacitados na FUNAI, o baixo orçamento e a falta de pessoal do judiciário, aliada à grande demanda de processos de todas as espécies, em todas as esferas deste poder, acabam gerando os impasses as demarcações definitivas, uma vez que os procedimentos administrativos não conseguem ser finalizados e, no final, grande parte destes processos vai parar no Poder Judiciário.

PALAVRAS-CHAVE: Povos indígenas. Demarcação. Direitos indígenas. Região Sul do Brasil.

1 Bacharel em Direito. Advogado. pejusti@hotmail.com.

2 Doutor em Direito - UFSC. Professor titular do Curso de Direito e Especializações da Universidade do Extremo Sul Catarinense - Unesc. Pesquisador do Núcleo de Estudos em Estado, Política e Direito. Vice-reitor da UNESC. Advogado. drp@ unesc.net. 


\section{ABSTRACT}

The proposed study aims to analyze the problem of demarcation of indigenous lands in the southern region of Brazil. Initially, the historical aspects, relevant concepts, constitutional rights and guarantees of indigenous peoples and interventionist policies in defense of these peoples were addressed. In this sense, the role of FUNAI as an organ directly responsible for the demarcations was highlighted, but, especially the current situation of the processes of regularization of indigenous areas. The deductive method in theoretical and qualitative exploration was used as a scientific methodology with the use of bibliographic and legal documentary material. It was found that one of the main obstacles to the effective demarcation of indigenous lands is linked to the absence of public policies, in which the interests of certain groups overlap with diffuse and collective interests. In addition, the lack of trained civil servants at FUNAl, the low budget and the lack of staff in the judiciary, coupled with the great demand for lawsuits of all kinds, in all spheres of this power, end up generating the impasses the definitive demarcations, a since administrative procedures cannot be finalized and, in the end, a large part of these processes will end up in the Judiciary.

KEYWORDS: Indigenous peoples. Demarcation. Indigenous rights. South region of Brazil.

\section{INTRODUÇÃO}

A ocupação e conquista do intitulado, "Novo Mundo", pelos conquistadores europeus em relação ao futuro continente Americano, visava a exploração de riquezas, principalmente os metais preciosos, ouro e prata. Estes metais, principalmente, o ouro constituía a base de medida de riqueza dos novos Estados Absolutistas do século XV.

Entretanto, os europeus encontraram neste "novo" território "descoberto" ao atravessarem o Oceano Atlântico, diversos povos originários com línguas, culturas, tradições e formas de organizações sociais distintas. Em determinadas regiões foram encontradas civilizações complexas em suas formas de organização social, outras com organizações mais tribais. Contudo, todas com modelos de organização social, totalmente distintas dos modelos europeus.

Num primeiro momento os conquistadores europeus necessitando do conhecimento destes povos sobre como sobreviver nesta "nova" terra buscam compreender e tolerar estes povos. Todavia, após os primeiros conflitos serem instalados e a necessidade europeia em explorar e escravizar os povos indígenas para forjarem o modelo econômico de exploração das riquezas da terra, teve o início dos grandes massacres.

Em nenhum momento de toda a história de ocupação e conquista do território americano a proteção aos direitos dos povos indígenas e a manutenção de suas terras esteve no escopo deste processo. Pelo contrário, o que foi instaurado foi um verdadeiro genocídio destes povos, com vistas a exterminar esta cultura e todo o seu direito sobre a sua terra e ao seu modo de vida milenar.

Ao longo dos períodos colonial, imperial, republicano, militar e por fim democrático, os povos indígenas foram ora ignorados, ora tratados como se não fossem seres humanos, ora tratados como incapazes, o que de certa forma ainda permanece, e não tiveram seus direitos respeitados, especialmente no que concerne o direito a terra. A Constituição de 1988 veio fortalecer algumas ideias e políticas que haviam surgido de 1910 em diante. No entanto, apenas com o advento da Constituição de 1988 é que se passou a dar real importância, ainda que 
em pequena escala, aos direitos dos povos indígenas. 0 Estatuto do Índio foi recepcionado pela Constituição de 1988 e, embora ultrapassado, fortalece a necessidade de se garantir as condições de vida dos povos indígenas, tanto na forma de integração, que prevê o estatuto, quanto na forma de manter a sua identidade.

Assim, far-se-á a análise jurídica e fática da atual situação das populações indígenas no Brasil, mais especialmente no que tange as questões territoriais e a demarcação das terras indígenas, bem como, dos empecilhos políticos e jurídicos que por ventura possam prejudicar a efetivação das referidas demarcações, na região Sul do Brasil.

\section{TERRAS TRADICIONALMENTE INDÍGENAS E OS EFEITOS DA COLONIZAÇÁO}

Inicialmente, cabe destacar que as ocupações européias ${ }^{3}$ causaram significativas modificações na cultura e demografia das diversas populações indígenas que residiam no país. As alterações demográficas se deram em função da própria colonização, com lutas em razão da demarcação e conquistas territoriais, doenças transmitidas pelos povos brancos, além da "[...] intensiva exploração da mão-de-obra indígena, como a escravidão [...]". (COLAÇO, 2005, p.11-12).

As modificações culturais se deram em decorrência da falta de respeito pela cultura dos povos indígenas, que aos poucos foi sendo destruída, uma vez que os colonizadores passaram a impor sua própria cultura aos índios colonizados. Importantes alterações ocorreram para os povos indígenas, especialmente, no que tange a evangelização, com consequências significativas em sua cultura, uma vez que a vinda dos Jesuítas culminou com uma modificação significativa nas crenças religiosas impostas a partir daí. Os jesuítas, vindos da Europa, serviam primordialmente aos interesses da Monarquia Espanhola, "ocupando o território, defendendo as suas fronteiras, e, através do poder tutelar, atuando como eficiente veículo de divulgação da cultura cristã-ocidental européia". (COLAÇO, 1998, p.05).

Os europeus visualizavam os indígenas como seres completamente inferiores e sem capacidade alguma de governarem a si mesmos, inclusive, com a crença de que não havia sistema jurídico entre estes povos, o que se provou não ser real, com o passar dos anos e de muita análise. Assim, por meio da tutela que lhe impuseram os europeus, através dos jesuítas, justificavam o que chamaram, à época, de humanização. (COLAÇO, 1998, p.22).

É possível observar que desde o início das conquistas e colonizações européias, no "novo" continente americano, não houve observância dos direitos destes povos originários, ou dos sistemas jurídicos próprios das populações indígenas, impondo-se como primordial a implementação de situações e condições que visavam garantir a continuidade dos projetos dos colonizadores. Neste sentido, a busca por riquezas e a imposição da cultura, religião e civilidade dos dominantes, sem que atentassem para o fato de que os reais proprietários das

3 Os europeus, segundo a história, quando chegaram a América não sabiam que aqui estavam, acreditando que na realidade desembarcavam na Índia, inclusive tendo chamado os povos que aqui viviam de índios por tais motivos. Aliás, o próprio Cristóvão Colombo acabou morrendo, após duas viagens, acreditando que realmente havia chegado à Ásia. (GALEANO, 1980). 
terras encontradas à época, eram ocupadas e pelos povos que ali já se encontravam, com os direitos de uso e de ocupação pré-existentes já estabelecidos. (WOLKMER, 2001).

No caso da história da conquista e colonização do Brasil, por parte dos portugueses que aqui chegaram, encontraram povos nativos (originários), os quais de forma generalizada denominaram de índios e que possuíam história e cultura diversa dos povos europeus ${ }^{4}$. (COLAÇO, 2005).

Quando da chegada dos portugueses ao Brasil, diversas populações indígenas ocupavam o território, sendo que os Tupi-Guarani se encontravam predominantemente no litoral, onde aportaram primeiramente os conquistadores ${ }^{5}$ europeus provenientes de Portugal. Desta forma, foram os primeiros a sofrerem as interferências culturais e sociais, como um todo, dos povos europeus. Além disso, foram capturados e forçados a trabalhar para os colonizadores, ocorrendo assim a aniquilação de suas tradições, costumes, crenças, culturas e de sua história, que passou a se misturar com a história dos então invasores. (SANTOS, 1973)

Meira (2013, p. 103), destaca que, no Brasil, "o que vigorou de fato desde a Colônia até o Império foi uma forte redução da população indígena em razão de epidemias, guerras e exploração do trabalho indígena", não tendo existido, nos primeiros séculos, qualquer preocupação política, humanitária ou cultural, com estes povos.

Estes povos originários, além das tradições e culturas próprias, possuíam ordenamento jurídico, ou regras jurídicas, ainda que estas não fossem escritas ou que delas não se tenha real conhecimento. Pelo contrário, os povos indígenas encontrados no Brasil quando da sua colonização, detinham até então, normas de convívio elaboradas pelo próprio grupo ao qual pertenciam, que chamavam de tradição. Estas normas, ou tradições, deveriam ser respeitadas e seguidas, sob pena de o indivíduo que a desobedecesse, ser excluído e abandonado pelo grupo de que fazia parte, afinal, "[...] burlar os costumes seria desrespeitar os tabus, seria irar os deuses e a natureza [...]" e isto colocaria em risco tanto o indivíduo quanto o grupo como um todo. (COLAÇO, 2005, p. 23).

As instituições sociopolíticas e jurídicas destes povos originários indígenas atendiam as suas necessidades de solução de conflitos, de organização e convívio social por milênios. Estas instituições, se assim pode-se nomear, possuíam uma outra forma de organização e constituição totalmente distinta do modelo europeu do mesmo período. (MONTE, 1999, p. 17).

É necessário destacar que embora a evangelização e integração dos povos indígenas tenham suprimido tradições, costumes e sistema jurídico próprio destes povos, eles ainda mantêm traços de suas culturas próprias, o que acaba por transformá-los em exemplo de resistência ao sistema de monismo jurídico imposto pelos colonizadores. (MONTE, 1999).

As primeiras normas que regeram as situações dos povos indígenas encontrados no Brasil, foram as cartas trocadas entre as colônias e seus territórios, sendo que no caso do

4 Aos olhos dos europeus, os indígenas eram seres inferiores e incapazes de se autogovernar; assim, através do regime tutelar Ihes trariam a civilização e a conseqüente [sic] "humanização", legitimando a transmissão e a interferência cultural, inserindo-os em nova ordem sócio-cultural. (COLAÇO, 2005, p. 13).

5 "O termo "descoberto", que por um longo período foi utilizado pela história oficial latino-americana, desconsidera de forma preconceituosa e arbitraria os povos originários que habitavam o continente americano. Para a abordagem no presente estudo, optou-se pelo uso da palavra "conquista", a qual representa de forma mais fidedigna a realidade que se passou naquela época." (PREVE, 2019, p. 148). 
Brasil, cumpre frisar que se tratava do Império Português, por meio da Carta Régia de 09, de abril, de 1655 e, posteriormente a Lei Pombalina de 1755. A referida Carta Régia estabelecida determinados direitos aos indígenas, mas paradoxalmente, permitia determinadas situações para que os fossem escravizados. (ALENCAR, 2015, p.01)

A primeira norma jurídica que trouxe alguma segurança aos povos indígenas, foi a Lei Imperial 601 de 1850, que reservava a estes povos as terras dos aldeamentos ${ }^{6}$, que se resumiam em agrupamentos de várias etnias, incluindo as indígenas, em determinada área de terra, com a finalidade, especialmente, de manter o controle e a catequização dos povos ali aglomerados. (ALENCAR, 2015, p. 01).

Os chamados aldeamentos fizeram surgir o que se denominou "Diretório dos Índios", à época criado pelo Marquês de Pombal, em meados de 1757, que perduraria até 1798, tendo, durante este período, instituindo-se políticas que se resumiam a confinar as populações indígenas em pequenos conglomerados de terras, que, em regra, se limitavam aos arredores de suas pequenas aldeias. "Esta política, associada à praxe de transformar todos os demais espaços em terras devolutas sobre as quais se permitia a titulação a terceiros, vai gerar o caos fundiário, de fato e de direito, no qual os índios se viram envolvidos". (ARAUJO, 2006, p. 25).

A Constituição de 1891, não trouxe qualquer modificação na situação jurídica, humana, política e nacional, dos povos indígenas. Apenas em 1910, foi criado o SPI - Serviço de Proteção ao Índio - comandado por Marechal Rondon, que passou a trazer certa paz e segurança aos povos nativos do Brasil, até então, não considerados integrantes do povo brasileiro. (ALENCAR, 2015, p.01).

Apenas em 1934, os índios passaram a possuir proteção jurídica efetiva, sendo que o texto da Constituição daquele ano, estabelecia a competência privativa da União legislar sobre a incorporação dos silvícolas à comunhão nacional, em seu art. $5^{\circ}$, e em seu artigo 129, estabelecia o "(...) respeito a posse de terras de silvícolas que nelas se achem, permanentemente localizados, sendo-lhes, no entanto, vedado aliená-las." (BRASIL, 1934).

Novas alterações em relação à questão indígena somente serão observadas na Constituição seguinte, de 1967, e a Emenda Constitucional de 1969, as quais mantiveram tais dispositivos, acrescentando, ainda, no artigo 186 da citada Constituição, que as terras indígenas passavam a pertencer aos bens da União. Enquanto isso, a Emenda de 1969 incluiu no artigo 198 a nulidade dos efeitos jurídicos de domínio, posse ou ocupação por terceiros das terras indígenas sem direito a ação ou indenização contra a União e a FUNAI. (ALENCAR, 2015, p. 1).

Em 1988, com a entrada em vigor da atual Constituição Brasileira, os povos indígenas passaram a ter um capítulo inteiro protegendo-os, bem como seus legados, além de artigos espalhados no texto constitucional, a exemplo do artigo 231, que protege e garante aos povos indígenas, suas línguas, costumes, tradições, direitos a terras originalmente e tradicionalmente por eles ocupadas, reconhecendo-os como organização social. (ALENCAR, 2015).

6 Aldeamento: destinação de áreas onde eram reunidas comunidades indígenas sob a administração de ordens religiosas (especialmente de jesuítas) e que seguiam o chamado Regimento das Missões, de 1686, visando em especial facilitar o trabalho de assistência religiosa, ou catequese. (ARAUJO, 2006, p. 25). 
Em se tratando dos conceitos relevantes para a compreensão do trabalho proposto, é possível encontrá-los na Lei 6.001/73, que dispõe sobre o estatuto do índio. Assim, é necessário que tais conceitos sejam aqui explicitados, conforme a seguir.

A legislação em comento, em seu artigo $3^{\circ}$, inciso I, descreve como índio, ou silvícola, todo e qualquer indivíduo que possua origem e ascendência pré-colombiana e que possa ser identificado como pertencente a um grupo étnico sendo que suas características culturais possam distingui-lo da sociedade nacional. Ainda, no inciso II, do mesmo artigo encontra-se a descrição de que Comunidade Indígena, ou Grupo Tribal, se caracteriza quando um conjunto de famílias ou comunidades índias, que vivam tanto em isolamento completo quanto em contato permanente, ou não, com outros setores e conjuntos sociais, não estão a estes últimos integrados.

0 artigo $4^{\circ}$ da Lei $6.001 / 73$ explica, ainda, que as populações indígenas serão consideradas isoladas quando vivem em grupos desconhecidos ou, ainda, quando destes grupos se tem poucas e vagas informações, geralmente por meio de contatos eventuais com elementos da comunhão nacional.

De outro lado, os índios são considerados integrados quando congregados à comunhão nacional e perfilhados no pleno exercício de todos os direitos civis, ainda que mantenham seus próprios usos, costumes e tradições. E, estando eles em contato permanente ou intermitente com grupos estranhos, e conservando parte das condições de sua vida aborígine, mas estando abertos a aceitarem determinadas práticas e estilos de vida comuns aos demais setores da comunhão nacional, da qual vão se tornando cada vez mais dependentes para o sustento próprio, pode-se dizer que se encontram em vias de integração. (FUNAI, 2018).

No que se refere ao conceito de terras indígenas, a Lei n. 6.001/73 traz em seu artigo 17, as seguintes imposições legais:

Art. 17. Reputam-se terras indígenas:

I - as terras ocupadas ou habitadas pelos silvícolas, a que se referem os artigos $4^{\circ}$, IV, e 198, da Constituição;

II - as áreas reservadas de que trata o Capítulo III deste Título;

III - as terras de domínio das comunidades indígenas ou de silvícolas. (BRASIL, 1973).

As terras ocupadas são aquelas que tradicionalmente já são habitadas e usadas pelas populações indígenas, ainda que não existam ações demarcatórias ou, nem mesmo reconhecimento por parte do Estado. (CAVALCANTE, 2016).

Consoante o entendimento de Cavalcante (2016), quando se fala das terras reservadas, descritas no capítulo III da Lei $6.001 / 73$, se está a fazer referência às terras denominadas expressamente de reservas indígenas, que são demarcadas pelo poder estatal para que os índios possam ocupá-las e delas se apossarem, independente se já havia por parte destes povos ocupação previa.

Já as terras de domínio das comunidades indígenas ou de silvícolas dizem respeito especificamente aos territórios dominiais, ou seja, que pertencem efetivamente, com titularidade registral, aos índios, o que na realidade, ocorre em raros casos. Em contrapartida, as duas espécies acima descritas, ou seja, as terras de ocupação tradicional e as reservas indí- 
genas, pertencem efetivamente à União, sem título de propriedade às populações indígenas. (CAVALCANTE, 2016).

No final do século XIX, quando os imigrantes europeus passaram a vir trabalhar no Brasil, após a abolição da escravatura, observou-se no sudeste e sul no país, mais especificamente nos Estados de São Paulo, Paraná e Santa Catarina, o surgimento de inúmeros conflitos com os povos indígenas que foram sendo expulsos de seus territórios pelos imigrantes que aqui chegavam. (MEIRA, 2013, p. 104).

Já no fim do século anterior e início do século XX, o governo brasileiro decidiu expandir suas linhas telegráficas em relação ao oeste/noroeste, em direção ao Mato Grosso, culminando com a entrada dos funcionários em território ainda não explorados, o que fez com que se passasse a ter conhecimento de inúmeras tribos e populações indígenas até então desconhecidas. Nesse contexto surgiu a figura de Candido Rondon, militar que passaria a defender os povos indígenas e lutar contra os atos de extermínio destas populações que ocorriam intensamente nas regiões sul e sudeste. "Seu lema 'morrer se preciso for, matar nunca' se tornou legendário". (MEIRA, 2013, p. 104).

Devido à grande influência de Candido Rondon, em 1910 seus argumentos foram capazes de influenciar o governo ao ponto de criar o Serviço de Proteção aos Índios e Localização dos Trabalhadores Nacionais (SPILTN), que ficou conhecido como SPI, a partir de 1918, que perduraria até 1967, conforme já destacado anteriormente. (MEIRA, 2013, p. 105).

Necessário, também se faz o destaque em relação as políticas intervencionistas de proteção aos povos indígenas no Brasil. Um dos principais marcos neste sentido foi a criação do Serviço de Proteção aos Índios, criado em 1910, não teve qualquer chance de reconhecer aos povos indígenas seus direitos, especialmente à terra, conforme determinava a nova legislação vigente à época. Em 1910 houve o movimento de reconhecimento das terras indígenas, o que deveria ser feitos pelos Estados-membros da União e seus respectivos municípios. Contudo, como as terras haviam sido transformadas em devolutas, e, consequentemente a Coroa Portuguesa as havia transferido a quem Ihe interessasse, tornava-se difícil a demarcação dos territórios para ocupação dos povos indígenas (ARAUJO, 2006, p. 27).

As reais mudanças, iniciaram-se entre 1967 e 1969, com a Constituição de 67 e a Emenda Constitucional de 69, que declararam as terras indígenas como sendo patrimônio da União, afastando, ao menos, a continuidade dos esbulhos praticados pelos entes federados e particulares aliados aos seus governos. Ademais, os dispositivos legais passaram a garantir o usufruto exclusivo dos recursos naturais que por ventura existissem nas terras por eles ocupadas, além de expressamente anularem os atos que tivessem incidência sobre as terras ocupadas pelos indígenas, sem qualquer indenização ou entendimento de direito adquirido. (ARAUJO, 2006, p. 30).

Ainda que os discursos protecionistas fossem acirrados, na prática o governo militar não cumpriu com as promessas de fiscalização e punição dos culpados pela dilapidação do patrimônio dos indígenas e descumprimento dos dispositivos legais, culminando, em 1967, com a extinção do SPI, e, concomitantemente, com a criação da FUNAI - Fundação Nacional do Índio. (ARAUJO, 2006, p. 31).

A FUNAI, no entanto, viria a ser erguida nas bases do SPI, seguindo, aliás, as mesmas diretrizes e funcionamento, o que, na prática não trouxe, na época, nenhum resultado dife- 
rente. A situação e a pressão no governo acabaram por obrigar que o governo militar elaborasse legislação específica para defender os interesses dos povos indígenas, quando então, em 1973, entrou em vigor a Lei 6001, denominado Estatuto do Índio. (ARAUJO, 2006, p. 31-32).

O Estatuto do Índio traz como premissa, a integração progressiva e harmoniosa dos povos indígenas à sociedade e ao ordenamento jurídico brasileiro. "Em outras palavras, o objetivo do Estatuto era fazer com que os índios paulatinamente deixassem de ser índios". (ARAUJO, 2006, p. 32).

Contudo, a partir de 1988 a FUNAI passou a ser uma espécie de tutora dos povos indígenas, como se estes fossem totalmente ou relativamente incapazes, inclusive, com certa dificuldade para que o judiciário da época entendesse a possibilidade dos índios escolherem seus próprios representantes, especialmente advogados, sendo que estes sofriam com a necessidade de sempre esclarecer seus interesses quanto a representação daqueles, junto a autoridade policiais e judiciais. (ARAUJO, 2006, p. 41-42).

Séculos após a colonização vislumbra-se, atualmente, a existência da PNPPPI - Política Nacional de Promoção e Proteção dos Povos Indígenas - constata-se que embora o discurso protecionista seja difundido há muito tempo, é possível observar, nos últimos anos, a crescente preocupação com os reais direitos e garantias previstos na Constituição, ao menos, em tese. (FUNAI, 2018).

Consoante se extrai do tópico política indigenista, no Portal do Ministério da Justiça, é necessário destacar que inúmeras normas vêm sendo elaboradas com o intuito de garantir real proteção aos índios, inclusive, com desconcentração e descentralização das políticas pertinentes em relação, por exemplo a educação voltada para os povos indígenas e as questões acerca da saúde indígena. (FUNAl, 2018).

Ocorre, no entanto, que por mais valorosa e intensa que seja a elaboração de legislação capaz de garantir direitos e políticas públicas aos índios, somente a execução e fiscalização constante destas normas é que serão capazes de elidir o abandono pátrio ao qual estão sujeitos os povos indígenas. Como todos os setores nacionais, as populações indígenas carecem de maior atenção e efetiva realização de atos administrativos capazes de causarem impactos verdadeiros no que se refere às garantias e aos direitos constitucionais, conforme abordagem a seguir.

Nesse sentido, pela magnitude e impactos gerados a partir da vigência da Constituição brasileira de 1988 para os direitos e garantias fundamentais dos povos indígenas faz-se necessário alguns destaques. Isto porque a Constituição de 1988 instaurou o reconhecimento aos povos indígenas direitos coletivos e permanentes, “(...) criando as bases para o estabelecimento do direito de uma sociedade pluriétnica e multicultural, em que povos continuem a existir como povos que são, independente do grau de contato ou de interação que exerçam com os demais setores da sociedade." (ARAUJO, 2006, p. 45).

O texto Constitucional de 1988, principalmente, no disposto no artigo 231, vem reconhecer os direitos dos índios em relação a organização social, costumes, línguas, crenças e tradições, e os direitos originários sobre as terras que tradicionalmente ocupam, determinando que a União é responsável pela proteção e demarcação das terras indígenas.

Depreende-se, portanto, do texto expresso na Carta Magna, que os povos indígenas passaram a possuir maior proteção, ao menos em tese, em relação aos seus direitos indi- 
viduais e coletivos, bem como, em relação as terras consideradas de ocupação tradicional, sendo que cabe à União zelar por tais direitos.

Os direitos previstos no artigo acima transcrito podem traduzir-se em direitos extra patrimoniais, como direito à organização social, aos costumes, às línguas, crenças e tradições, ou seja, de forma mais resumida, direito à diferença, e, direito patrimonial, que se resume no direito à terra, sendo estes últimos considerados originários, o que equivale a dizer que antecedem a criação do próprio Estado. (OLIVEIRA, 2017).

É possível constatar, portanto, que a Constituição de 1988 trouxe determinações importantes no que se refere aos direitos e garantias dos povos indígenas, sobretudo no que tange as terras tradicionalmente ocupadas por estes povos, garantindo-Ihes, de certa forma, que seus bens culturais e tradicionais sejam mantidos e preservados.

Desse modo, a Constituição de 1988, mais especificamente em seu artigo 231, vem assegurar direitos dos povos indígenas às suas terras tradicionalmente ocupadas, ante a ausência de normas expressos, o que acabava causando diversas inseguranças jurídicas aos interessados. Neste sentido, é possível constatar que mesmo com as garantias e proteções de direitos relacionados aos povos indígenas pela Constituição de 1988, a história social de formação do Estado brasileiro, desde o período colonial, ainda marca a sociedade com profundas desigualdades sociais vividas entre o seu povo. (CUSTÓDIO; LIMA, 2009, p. 286).

Ademais, deve ser destaca que o Direito sempre esteve a serviço (e ainda está), e foi elaborado, em sua maior parte, por uma elite social burguesa sedenta de poder. "A produção normativa teve como uma de suas funções o exercício do controle social sobre as classes menos favorecidas, escamoteada por interesses políticos e econômicos." (CUSTÓDIO; LIMA, 2009, p. 286).

Todavia, é inegável constatar os avanços proporcionados pela Carta Constitucional de 1988. A partir deste diploma legal, diversas legislações complementares e ordinárias desdobraram-se da mesma. Desta forma, para reforçar os dispositivos legais que tratam das questões de demarcação das terras indígenas, agora assegurados constitucionalmente, frisa-se a existência do Decreto 1.775/96, que dispõe sobre os procedimentos administrativos das referidas demarcações; o Decreto 5051/2004, que promulgou a Convenção 169 da Organização Internacional do Trabalho - OIT, sobre os povos indígenas; a Portaria MJ nº 14/96, que veio estabelecer regras sobre a elaboração do relatório circunstanciado de identificação e delimitação das terras indígenas; a Portaria MJ n² 2498/11, que regulamenta a participação dos entes federados no âmbito do processo administrativo de demarcação de terras indígenas; a Instrução Normativa da FUNAI n 02/2012, que institui a Comissão Permanente de análise de Benfeitorias - CPAB - e estabelece o procedimento para indenização das benfeitorias implantadas no interior de terras indígenas; e, por fim, a Portaria 682/PRES - FUNAI, de 24 de junho de 2008, que estabelece o Manual de Demarcação Física de terras indígenas.

Ademais, insta consignar que a função precípua do FUNAI, desde a sua criação, mas especialmente após a entrada em vigor da Lei 6001/73, sempre foi a de tutelar os interesses dos povos indígenas, bem como, seus patrimônios, considerando-os relativamente incapazes de praticar os atos de representação própria. (ARAUJO, 2006). 
Diante do que fora tratado até o momento, e com base na posição de Araujo (2006), verifica-se que várias medidas vem sendo tomadas, nos últimos anos para que as populações indígenas tenham seu direito à terra respeitado, sendo que deste deriva o respeito aos demais aspectos intrínsecos aos povos indígenas, como os costumes, tradições, cultura, religião, etc. Se as legislações, embora ainda precárias no sentido de proteção, vem trazendo alento aos anseios territoriais dos indígenas, é preciso que as condutas e procedimentos sejam mais viáveis e ágeis.

Assim, não se estaria permitindo, por outro lado, que "um ou outro" possuíssem poder absoluto sobre as decisões que deferem, ou não, os processos administrativos de demarcação das terras indígenas, evitando-se, desta forma, que erros permaneçam cerceando os povos indígenas de exercerem efetivamente o poder que lhes cabe em suas terras.

\section{OS OBSTÁCULOS JURÍDICOS E POLÍTICOS PARA DEMARCAÇÃO DE TERRAS INDÍGENAS NO SUL DO BRASIL}

Não é possível precisar a época em que os primeiros habitantes passaram a ocupar os territórios na América do Sul, e, consequentemente, no sul do Brasil, embora se estime, por meio dos estudos antropológicos, que a presença humana data, na região sul do país, de 13 (treze) mil anos, migrando da América do Norte para regiões da América do Sul, e, posteriormente, se instalando na região sul brasileira. (LISBOA, 2010).

Os primeiros registros escritos dos povos indígenas na região sul do Brasil datam de 1626 e 1630, quando os jesuítas, os colonizadores e políticos passaram a migrar para esta região em missões que, ao que indica a história, tinham como principal objetivo colocar fim as disputas da região entre as Coroas Portuguesa e a Espanhola. (LISBOA, 2010).

Em relação aos povos indígenas encontrados quando da ocupação do Sul do Brasil pelos europeus destacam-se os Kaingang, Xokleng e Guarani. (LISBOA, 2010, p. 31). Os conflitos com estes povos e o colonizador europeu tiveram como principal elemento de disputa a ocupação das terras dos indígenas.

Nesse processo de conflitos instaurados, aponta-se a figura social dos chamados bugreiros, que nada mais eram do que caçadores de índios, já que estes, acuados e com suas áreas e territórios sendo ocupados, destruídos e suas glebas de terras cada vez menores, passaram a atacar o gado e as fazendas dos colonos em busca de saqueá-las para sobrevivência. A forma como os referidos bugreiros agiam, exterminando e massacrando as populações indígenas, teve destaque na região sul do Brasil, uma vez que o Estado era incapaz de prover a segurança que os colonizadores exigiam. (LISBOA, 2010).

Apenas com a criação de órgão oficiais indigenistas, como o SPI, por exemplo, é que se observou o início da demarcação de terras indígenas nos territórios do sul do Brasil, e que, apesar de não terem cumprido seu papel, em muitas circunstâncias, como se destacou anteriormente, acabaram por impedir que massacres maiores fossem cometidos contra os povo indígenas e que, de alguma forma, fossem iniciadas as demarcações de suas terras como passava a prever a legislação vigente à época. (LISBOA, 2010). 
Dessa forma, a partir do disposto na Constituição de 1988 e no Decreto n. 1775/96, o processo de demarcação de terras indígenas constitui-se como um procedimento administrativo com objetivo de identificar e sinalizar os limites das áreas tradicionalmente ocupadas pelas populações indígenas. Em relação ao decreto citado, no entendimento de Araujo (2006), o procedimento de demarcação das terras indígenas, estabelecido no decreto 1775/96, divide-se em algumas etapas.

A primeira etapa é a da identificação, onde a FUNAI nomeia um antropólogo que irá elaborar o estudo na área a ser demarcada. Este estudo irá embasar o trabalho de um grupo técnico escolhido, preferencialmente formado por membros do órgão indigenista, em regra, a FUNAI, "que fará estudos complementares de natureza etno-histórica, sociológica, jurídica, cartográfica e ambiental, além do levantamento fundiário para a delimitação dos limites da Terra Indígena". O trabalho realizado deverá ser apresentado ao presidente da Fundação Nacional do Índio, que o aprovará, publicando-se o documento oficial em seguida, além de fixação em mural público no Município onde ocorre a demarcação. (ARAUJO, 2006, p.50).

A segunda etapa é denominada de contraditório. É o momento seguinte, em que, feita a publicação e afixado o edital em mural municipal, abre-se a oportunidade dos Estados, Municípios, ou qualquer outro interessado impugnar o procedimento de demarcação, dentro do prazo de 90 (noventa) dias a contar da publicação, requerendo e apresentando provas que possam estabelecer indenização ou apontarem vícios no relatório técnico. "A FUNAI tem, a partir daí, 60 dias para opinar sobre as razões dos interessados e encaminhar o procedimento ao Ministro da Justiça". (ARAUJO, 2006, p. 50).

Em seguida, na terceira etapa, tem-se a declaração dos limites, que é o momento em que o Ministro da Justiça, no prazo de 30 (trinta) dias, deverá fazer a declaração dos limites definidos no estudo técnico, e, por fim, determinar a demarcação física do território em questão. "Ao invés disso, porém, poderá optar por prescrever diligências a serem cumpridas em mais 90 dias, ou ainda, desaprovar a identificação por meio de decisão fundamentada, a ser também publicada na imprensa oficial". (ARAUJO, 2006, p. 50).

Ultrapassadas as etapas anteriores e tendo o Ministro da Justiça declarado os limites, sem qualquer pedido de diligências ou desaprovado a identificação, nos moldes anteriormente explicados, segue-se a etapa da demarcação física.

Esta etapa será feita pela FUNAI, que fará a colocação de marcos físicos, colocação de placas, picadas na vegetação, dentre outras formas de marcar os limites da área definida no estudo técnico. "Ainda nesta etapa, o INCRA (Instituto Nacional de Colonização e Reforma Agrária), em caráter prioritário, procederá ao reassentamento de eventuais ocupantes não-índios". (ARAUJO, 2006, p. 50-51).

A quinta etapa é a da Homologação, sendo que "todo o procedimento de demarcação será, por fim, submetido ao Presidente da República para ratificação por meio de decreto". (ARAUJO, 2006, p. 51).

Por fim, a sexta e última etapa consiste no Registro. "A Terra Indígena demarcada e homologada será registrada, no prazo de 30 dias, no cartório de registro de imóveis da comarca correspondente e no SPU - Secretaria de Patrimônio da União". (ARAUJO, 2006, p. $51)$. 
Desta forma, o procedimento administrativo de demarcação das terras indígenas pode ser considerado ato de natureza meramente declaratória. Ou seja, o ato administrativo de demarcação das terras indígenas não constitui qualquer direito, mas, tão somente, reconhece um direito já existente, que, conforme acima descrito, é um direito originário, advindo da própria Constituição de 1988.

Além disso, como as terras indígenas passaram a ser consideradas bens da União, são, conforme já dito anteriormente, inalienáveis e indisponíveis, bem como, os direitos sobre elas tornaram-se imprescritíveis, sendo que abrigam, atualmente, cerca de 300 povos indígenas em todo território nacional. É possível observar na atualidade, 462 terras indígenas regularizadas no Brasil, ocupando em torno de 12,2\% do território nacional, sendo a maior concentração na área chamada Amazônia Legal. Destas áreas as Regiões Sul e Sudeste possuem o menor percentual de distribuição. (FUNAI, 2018).

Nas áreas de maior impacto resultantes da colonização, que se desenvolveram economicamente de forma galopante, a posse dos índios manteve-se de forma reduzida e esparsa, sem levar em conta as reais necessidades destes povos para manutenção do seu modo de vida e sua sobrevivência. É justamente em regiões como a do Mato Grosso do Sul, e mais especialmente os Estados do Paraná, Santa Catarina e Rio Grande do Sul que existem as maiores incidências de conflitos no que concerne a regularização fundiária das terras indígenas e disputas territoriais.

Em relação as políticas de incentivo da regularização das terras indígenas, extrai-se do Portal da FUNAl:

Isso se dá a partir de políticas específicas, incentivos fiscais e repasse de recursos federais exclusivamente destinados às terras indígenas e às políticas indigenistas desenvolvidas dentro e fora das terras indígenas (como, por exemplo: ICMS ecológico, repasses relacionados à gestão territorial e ambiental de terras indígenas, repasses relacionados à educação escolar indígena, recursos relacionados às políticas habitacionais voltadas às terras indígenas, recursos destinados a ações de etno desenvolvimento, fomento à produção indígena e assistência técnica agrícola em terras indígenas etc.). Especialmente nos estados e municípios localizados em faixa de fronteira, a demarcação de terras indígenas garante uma maior presença e controle estatal nessas áreas especialmente vulneráveis e, em muitos casos, de remoto acesso. (FUNAI, 2018).

Observa-se no texto acima que a União, responsável por garantir a aplicação das normas constitucionais e infraconstitucionais, possui políticas de incentivo aos Municípios e aos Estados para que estes implementem e assegurem as demarcações e regularizações das áreas indígenas, inclusive, com repasses de recursos e incentivos fiscais.

Além dos incentivos fiscais e repasses de recursos que beneficiam os entes federados, a regularização das terras indígenas trazem, ainda que indiretamente, benefício à sociedade como um todo, a começar pela diminuição dos conflitos sobre as terras, passando por entender que estas regularizações contribuem para a construção de uma sociedade pluriétnica e multicultural, e, por fim, mantendo vivas as tradições e modo de vida das populações indígenas, que acabam por enriquecer o patrimônio cultural do país. (FUNAI, 2018).

Além de todos os benefícios e reconhecimento de direito da dignidade humana dos índios, é preciso ressaltar que a demarcação das terras indígenas traz benefícios ao meio 
ambiente, e assim, tem impacto direito na comunidade internacional, já que as terras dos índios mantêm como as mais protegidas ambientalmente.

Todavia, segundo Barros e Barcelos (2016), a FUNAI enfrenta dificuldades múltiplas em seu aparelhamento, especialmente no que se refere à falta de servidores e pessoal qualificado para realização dos procedimentos exigidos para a demarcação, que fica, em regra, a encargo da Fundação.

É possível identificar como principais entraves para demarcação e regularização das áreas indígenas, segundo Barros e Barcelos (2016), as restrições orçamentárias e de pessoal na FUNAI, além de pressões políticas que asfixiam o direito constitucional à terra, a principal reivindicação desses povos.

Conforme declaração dos funcionários, por meio de carta enviada ao Poder Público e a imprensa, em 2016, a FUNAI conta com 7 Coordenações Regionais (CR's) e 297 Coordenações Técnicas Locais (CTL's), unidades descentralizadas próximas aos indígenas, sendo que em muitas destas Coordenações Técnicas Locais não existem funcionários, e quando existem, não passam de três. (BARROS E BARCELOS, 2016).

Existem relatos, inclusive de casos no Paraná em que os prefeitos de diversos Municípios reuniam-se para coagir e ameaçar a vida de funcionários das CTL's, que tiveram, inclusive, que deixar as regiões, indo instalar-se em Brasília. (BARROS E BARCELOS, 2016).

Mais do que os entraves causados pela falta de estrutura da FUNAI, é preciso atentar para o fato de que os maiores obstáculos para efetivação da demarcação e regularização das terras indígenas se encontram na disputa política e econômica.

As bancadas ruralistas e do agronegócio são os maiores empecilhos a concretização das demarcações das terras indígenas, uma vez que, movidos por interesses próprios, os proprietários de terras voltadas a agricultura e a pecuária, além das grandes empresas madeireiras e mineradoras, dentre outras empresas ligadas à extração de recursos naturais, pressionam politicamente o governo para que as regularizações não afetem o andamento de seus negócios.

Na Região Sul do Brasil, os processos de demarcações encontram inúmeros obstáculos, especialmente pela grande quantidade de títulos de propriedade registrados. Essa suposta regularidade das terras devidamente registradas em nome de proprietários que as ocuparam ou obtiveram seus títulos há muitas décadas, faz com que as pressões políticas se tornem mais acirradas, inclusive, com maior facilidade de articulações no Judiciário. (BARROS E BARCELOS, 2016).

"Num contexto de reprimarização das exportações do país, que passou a depender ainda mais das commodities agrícolas e minerárias, a contradição com a pauta indígena se evidencia novamente." (BARROS E BARCELOS, 2016, p. 1).

Ademais, a máquina judiciária também se encontra, há muito, defasada em relação à quantidade de servidores, desde técnicos à Magistrados e membros do Ministério Público. Essa defasagem de servidores, como é sabido, torna a justiça brasileira exageradamente morosa, e, de uma forma ou outra, quase todos os processos administrativos de demarcação acabam gerando algum tipo de discussão no judiciário.

Escrevem Barros e Barcelos (2016, p. 01): 
Em 2014, foram anuladas demarcações de três terras indígenas após uma decisão da Segunda Turma do Supremo Tribunal Federal (STF). Duas dessas terras estão no epicentro da violência contra os povos indígenas, o Mato Grosso do Sul: a TI Guyraroka, dos povos Guarani e Kaiowá, e a TI Limão Verde, do povo Terena. Também a TI Porquinhos, do povo Canela- pãnjekra, do Maranhão, teve a demarcação anulada. O Supremo, porém, já adotou posições contrárias. Recentemente, o tribunal negou o seguimento de um mandado de segurança que pedia a revogação da demarcação da TI Morro dos Cavalos, em Santa Catarina, com base na tese do marco temporal.

Num contexto geral é possível constar que o Estado, como um todo, possui defasagem de funcionários e pessoal capacitado em todas as áreas, indo desde a FUNAI, que é responsável pelos estudos técnicos e etapas do processo administrativo de demarcação, findando no Poder Judiciário, onde acaba a maioria dos processos de demarcação.

Além da falta de estrutura do Estado, constata-se que os interesses particulares ainda tendem a se sobrepor aos interesses difusos e coletivos, já que um dos maiores, se não o maior obstáculo à demarcação e regularização das terras indígenas é o setor político e o econômico, no qual os empresários do agronegócio, e demais ramos ligados à extração de bens e produtos advindos da terra influenciam, por meio de suas bancadas, as decisões do Poder Executivo, do Legislativo e do Judiciário.

0 direito dos povos indígenas às terras, especialmente as que ocupam tradicionalmente, tem como objetivo respeitar as culturas e tradições dos povos originários, garantir a diminuição dos conflitos territoriais, promover a sustentabilidade e a preservação do meio ambiente além de assegurar que os Municípios e os Estados possam cumpram com suas obrigações de oferecer atendimento digno aos seus cidadãos. (FUNAI, 2018).

\section{CONSIDERAÇÓES FINAIS}

Durante os primeiros séculos de ocupação europeia no território brasileiro, os povos indígenas foram massacrados, mortos, escravizados e, em sua grande maioria, expulsos ou retirados das terras que ocupavam originalmente. Em nome do progresso, da civilização e dos interesses econômicos privados e governamentais, os povos indígenas passaram a perder suas tradições, costumes, religiões e formas de organizações primárias, embora, em grande parte, estes povos lutam para manter vivas as lembranças étnicas de seu povo.

Em relação aos procedimentos de demarcação de terras indígenas verifica-se que pouquíssimas condutas efetivas, pois os processos têm sido paralisados em razão de interesses de determinados grupos econômicos ou de grupos políticos. O desmonte da FUNAI como espaço público do Estado promotor de políticas públicas tem sofrido reduções e cortes de orçamento e de estrutura de pessoal. Tal fato, aliado a morosidade processual do Poder Judiciário e os incontáveis recursos disponíveis para terceiros interessados em impedir as demarcações, acabam por causar a demora na finalização dos processos demarcatórios das terras indígenas.

Em todo o Brasil, especialmente na Região Sul, os maiores obstáculos às demarcações e regularizações das terras indígenas encontram-se nos conflitos políticos e econômicos 
ligados aos interesses do agronegócio, tendo em vista de se tratar de uma região com alto capital especulativo da terra para a produção de commodities. Desfavorecendo, portanto, aqueles que são os ocupantes originários destes territórios e que acabam por ser marginalizados e excluídos de qualquer processo de reconhecimento dos seus direitos originários sobre a terra que vivem.

\section{REFERENCIAS}

ALENCAR, Adriana Vital Silva de. Evolução histórica dos direitos indígenas.

Revista Jus Navigandi, Teresina, jan. 2015. Disponível em:

https://jus.com.br/artigos/35348/evolucao-historica-dos-direitos-indigenas. Acesso em: 29 maio 2018.

ARAUJO, Ana Valéria et al. Povos indígenas e a lei dos brancos: o direito a diferença. Brasília: Ministério da Educação, Secretaria de Educação Continuada, Alfabetização e Diversidade, 2006. (Coleção Educação para Todos). Disponível em: http://portal.mec.gov.br/index.php?option=com_docman\&view=download\&alias=64

4-vol14povos-indigenas-pdf\&categoryslug=documentos-pdf\&ltemid=30192. Acesso em: 4 maio 2018.

BARROS, Ciro; BARCELOS, luri. A Funai pede socorrro. Revista on-line Carta Capital. jun. 2016. Seção Sociedade. Disponível em: https://www.cartacapital.com.br/sociedade/a-funaipede-socorro. Acesso em: 27 jun. 2018.

BRASIL. [Constituição (1988)]. Constituição da República Federativa do Brasil de 1988. Brasília, DF: Presidência da República. Disponível em: http://www.planalto.gov.br/ccivil_03/constituicao/constituicaocompilado.htm Acesso em: 4 maio 2018.

BRASIL. [Constituição (1934)]. Constituição dos Estados Unidos do Brasil de 1934. Brasília, DF: Presidência da República. Disponível em: http://www.planalto.gov.br/ccivil_03/constituicao/constituicao34.htm. Acesso em: 4 maio 2018.

BRASIL. [Constituição (1967)]. Constituição da República Federativa do Brasil de 1967. Brasília, DF: Presidência da República. Disponível em: http://www.planalto.gov.br/ccivil_03/constituicao/constituicao67.htm. Acesso em: 4 maio 2018.

BRASIL. Emenda Constitucional n. 1, de 17 de outubro de 1969. Edita o novo texto da Constituição Federal de 24 de janeiro de 1967. Brasília, DF: Presidência da República. Disponível em: http://www.planalto.gov.br/ccivil_03/ constituicao/Emendas/Emc_anterior1988/emc01-69.htm. Acesso em: 4 maio 2018.

BRASIL. Lei 6.001 de 19 de dezembro de 1973. Dispõe sobre o Estatuto do Índio. Brasília, DF: Presidência da República. Disponível em: http://www.planalto.gov.br/ccivil_03/leis/L6001.htm. Acesso em: 15 maio 2018.

BRASIL. Decreto 1.775 de 8 de janeiro de 1996. Dispõe sobre o procedimento administrativo de demarcação das terras indígenas e dá outras providências. Brasília, DF: Presidência da República. Disponível em: http://www.planalto.gov.br/ccivil_03/decreto/D1775.htm. Acesso em: 15 maio 2018.

CAVALCANTE, Thiago Leandro Vieira. Terra indígena: aspectos históricos da construção e aplicação de um conceito jurídico. Revista História, Franca, v. 35, p. 1-22, jul. 2016. Disponível em: http://www.scielo.br/pdf/his/ v35/0101-9074-his-35-00075.pdf. Acesso em: 12 abr. 2018.

COLAÇO, Thaís Luzia. O direito Guarani pré-colonial e as missões jesuíticas: a questão da incapacidade indígena e da tutela religiosa. 1998. 524 p. Tese (Doutorado em Direito) - Universidade Federal de Santa Catarina. Florianópolis, 1998. Disponível em: http://tede.ufsc.br/teses/PDPC0280-T.pdf Acesso em: 04 maio 2018.

COLAÇO, Thaís Luzia. "Incapacidade" indígena: tutela religiosa e violação do direito guarani nas missões jesuíticas. Curitiba: Juruá, 2005. 
CUSTÓDIO, André Viana; LIMA, Fernanda da Silva. O direito fundamental à titulação de terras das comunidades remanescentes de quilombos no Brasil. Revista Espaço Jurídico, Joaçaba, v. 10, n. 2, p. 275-298, jul./dez. 2019. Disponível em: https://portalperiodicos.unoesc.edu.br/espacojuridico/article/view/1931/999. Acesso em: 12 jun. 2018.

DALLARI, Dalmo de Abreu. Direitos humanos e cidadania. 2. ed. São Paulo: Editora Moderna, 2004.

FUNAI. Fundação Nacional do Índio. Entenda o processo de demarcação. Brasília, DF: Ministério da Justiça e Segurança Pública. Disponível em: http://www.funai.gov.br/index.php/2014-02-07-13-24-53. Acesso em 05 jun. 2018.

GALEANO, Eduardo. As veias abertas da América Latina. 8. ed. Rio de Janeiro: Paz e Terra, 1980.

LISBOA, João Francisco Kleba. O direito entre os Kaingang no Oeste de Santa Catarina: um olhar a partir da antropologia jurídica. 2010. 168 p. Dissertação (Mestrado em Direito) - Universidade Federal de Santa Catarina. Florianópolis, 2010. Disponível em: https://repositorio.ufsc.br/xmlui/handle/123456789/93900. Acesso em 10 jun. 2018.

MEIRA, Marcio. Direitos indígenas no Brasil: reveses, avanços e contradições. In: BOKANY, Vilma; VENTURI, Gustavo (Orgs.). Indígenas no Brasil: demandas dos povos e percepções da opinião pública. São Paulo: Editora Fundação Perseu Abramo, 2013. p. 101-125.

MONTE, Marcos Antônio Lorencette. O pluralismo jurídico e os povos indígenas no Brasil. 1999. 158 p. Dissertação (Mestrado em Direito) - Universidade Federal de Santa Catarina. Florianópolis, 1999. Disponível em: https:// repositorio.ufsc.br/xmlui/bitstream/handle/123456789/80658/150585.pdf?sequence=1\&isAllowed=y. Acesso em 10 jun. 2018.

OLIVEIRA, Cristiane de. Povos indígenas: conheça os direitos previstos na constituição. EBC, Brasília, abr. 2017. Notícias Direitos Humanos. Disponível em: http://agenciabrasil.ebc.com.br/direitos-humanos/noticia/2017-04/ povos-indigenasconheca-os-direitos-previstos-na-constituicao. Acesso em 10 jun. 2018.

PREVE, Daniel Ribeiro. Pluralismo jurídico e interculturalidade: os sistemas jurídicos indígenas latino-americanos e as formas alternativas na resolução de conflitos. Santa Cruz do Sul: Essere nel Mondo, 2019. Disponível em: http://www.esserenelmondo.com/pt/direito-pluralismo-jurldico-e-interculturalidade-ebook170.php. Acesso em 10 jan. 2020.

SANTOS, Silvio Coelho dos. Índios e brancos no sul do Brasil: dramática experiência dos Xokleng. Florianópolis: Luanrdelli Representações Ltda, 1973.

STAVENHAGEN, Rodolfo. Los pueblos indígenas y sus derechos. México: Unesco, 2007.

WOLKMER, Antônio Carlos. Pluralismo jurídico: fundamentos de uma nova cultura no direito. 3. ed. São Paulo: Editora Alfa Omega Ltda, 2001.

Recebido/Received: 03.04.2020.

Aprovado/Approved: 11.05.2020. 